\title{
A Raynaud Phenomonic Attack Induced After an Adult Diphtheria-Tetanus Vaccine
}

\author{
(i) Ahu Aksay1, () Mine Düzgöl2 , (i) Nuri Bayram², iliker Devrim² \\ ${ }^{1}$ Department of Pediatric Infectious Diseases, Cumhuriyet University, Sivas, Turkey \\ ${ }^{2}$ Department of Pediatric Infectious Diseases, Izmir Dr. Behcet Uz Children's Diseases and Surgery Training and Research Hospital, Izmir, Turkey
}

\begin{abstract}
Tetanus vaccine may cause systemic reactions, such as urticaria, anaphylaxis, and peripheral neuropathy or local reactions, such as erythema, endurance, and pain. We presented a 13-years-old patient who was administrated cyanosis, numbness, and coldness in both hands and forearms after one hour of vaccination adult-type diphtheria-tetanus from left deltoid muscle and evaluated vaccine side effects as Raynaud's phenomenon. Vaccine-induced Raynaud's phenomenon has not been reported in the literature, and this may be a side effect of the injection rather than the diphtheria-tetanus vaccine itself.

Keywords: Diphtheria-tetanus; Raynaud's phenomenon; side effects; vaccine.
\end{abstract}

$\mathrm{V}^{\mathrm{s}}$ accine preventive diseases have decreased significantly in many parts of the world with more frequent applications of vaccinations, but side effects related to vaccination have increased. Although vaccines are considered to be safe and effective, there may be some undesirable effects in practice. Post-vaccination side effects can be grouped into two main groups as local and systemic reactions. Redness, induration, susceptibility, ulceration, or abscesses can be counted as local reactions, while fever, hypersensitivity reactions and neurological complications are examples of systemic reactions [1]. We present a case of Raynaud's Phenomenon (RF) due to application of adult diphtheriatetanus $(\mathrm{Td})$ vaccine.

\section{Case Report}

A 13-year-old female patient was admitted to our hospital with complaints of bruising, numbness and coldness on both hands and forearms, especially on the left hand. It was learned that these symptoms started one hour after Td vaccination administered on the left deltoid muscle. The patient was being followed up by dermatology and rheumatology units for psoriasis and had no complaints related to psoriasis for six years, and her complaints were evaluated as unwanted effects due to vaccination. RF was considered in the foreground in the patient whose physical examination was normal except the presence of hypothermia, cyanosis and numbness in both hands (Fig. 1). The patient's body 
temperature and blood pressure were within normal limits. On palpation, brachial and radial artery pulses were within physiologic limits. The patient had no history of drug use. Her hemogram, liver transaminases, urea, creatinine, calcium, sodium and coagulation levels were normal. Venous Doppler ultrasonography was performed on both upper extremities to evaluate possible circulatory disorders. When the patient was evaluated together with her anamnesis, physical examination and tests, she was diagnosed with RF due to vaccination. Approximately eight hours after vaccination, all of his symptoms regressed (Fig. 2).

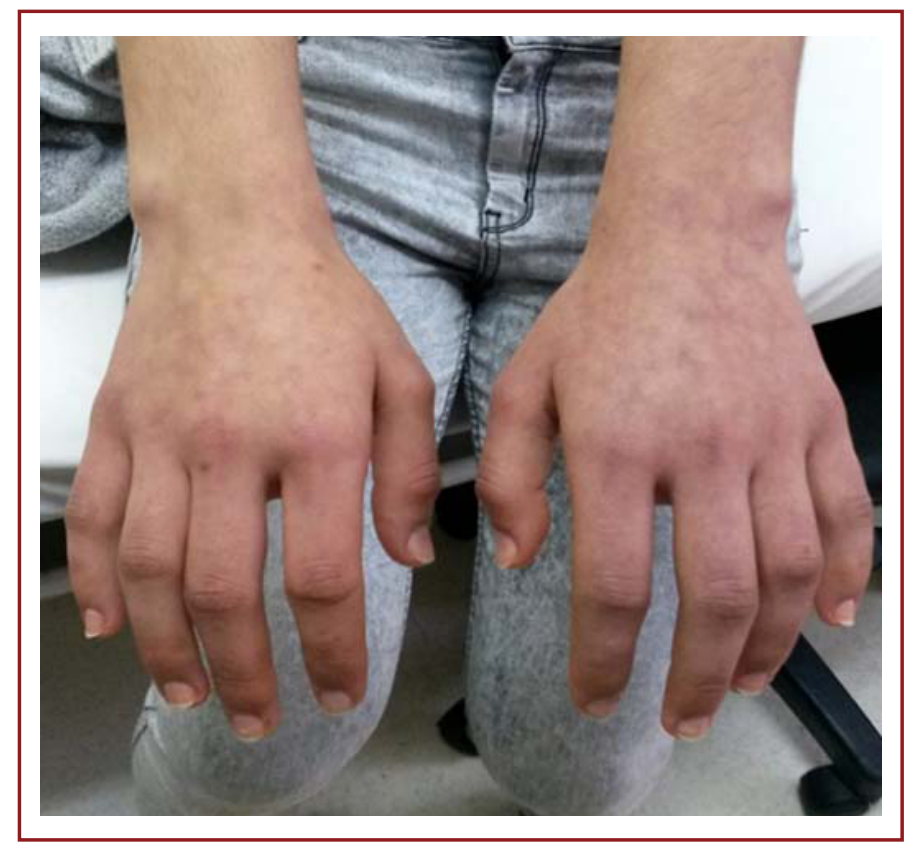

Figure 1. The appearance of Raynaud's phenomenon developed nearly one hour after vaccination.

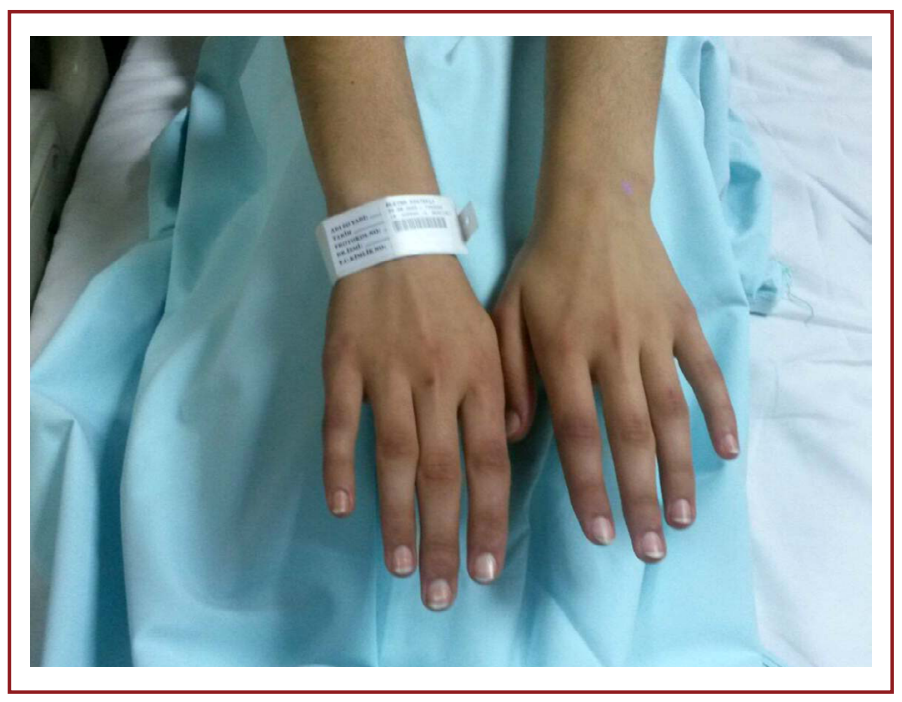

Figure 2. Photo that was taken after the resolution of patient's complaints, and symptoms.

\section{Discussion}

Vaccines are products developed as a result of long studies, and their efficacy and reliability are examined carefully before being put into use and they are subjected to very strict audits both in production and distribution stages. Mild local reactions and sometimes transient fever may occur after immunization. Undesirable effects after vaccination may be due in part to the vaccination itself, sometimes due to technical errors in vaccination or to a particular condition of the person being vaccinated. Generally, the majority of adverse events following vaccination are mild and nonlife-threatening short-term side effects. Serious side effects are very rare ${ }^{[1]}$. Local sensitivity, induration and erythema may occur after the adult diphtheria-tetanus vaccine. It has been reported that vaccination may induce systemic reactions as fever, drowsiness, anorexia, restlessness, headache, brachial neuritis, anaphylaxis ${ }^{[2]}$.

Raynaud's phenomenon is a vasospastic disorder characterized by discoloration, pain and paresthesia, typically resulting from cold and emotional stress. Usually, Raynaud's phenomenon involves the upper extremity, and sometimes symmetrically arteries and arterioles of the lower extremities. It is five times more common in women than men and usually occurs under the age of $40^{[3,4]}$.

Raynaud's phenomenon is most commonly seen in patients with systemic sclerosis among connective tissue diseases, but it can also be detected in other connective tissue diseases ${ }^{[3-5]}$. It was thought that our patient might be susceptible to developing RF due to her follow-up with the diagnosis of psoriasis. It was thought that the pain and emotional stress caused by the vaccination-induced the development of the patient's symptoms which should be considered as the first episode of an RF accompanying psoriasis and accordingly, follow-up of the patient was suggested. In the literature, there were no reports of RF related to vaccines, including $\mathrm{Td}$, and we thought that this case might be a side effect of erroneous injection technique rather than an adverse effect of Td vaccine.

Informed Consent: Written informed consent was obtained from the parents of the patient for the publication of the case report and the accompanying images.

Peer-review: Externally peer-reviewed.

Conflict of Interest: None declared.

Authorship Contributions: Concept: A.A., D.I.; Design: A.A., D.I.; Data Collection or Processing: A.A., D.I., D.M.; Analysis or Interpretation: A.A., D.I.; Literature Search: A.A., D.I., B.N., D.M.; Writing: A.A., D.I., B.N. 
Financial Disclosure: The authors declared that this study received no financial support.

\section{References}

1. American Academy of Pediatrics. Active immunization. In: Peter G, editor. 2012 Red Book: Report of the commitee on Infections Diseases. 25th ed. Elk Grove Village, IL: American Academy of Pediatrics; 2012:11-55.

2. Lee SY, Kwak GY, Nam CH, Kim JH, Hur JK, Lee KY, et al. Immunogenicity and safety of diphtheria-tetanus vaccine in pre-adolescent and adolescent South Koreans. Vaccine 2009; 27:3209-12.

3. Linnemann B, Erbe M. Raynaud's phenomenon-assessment and differential diagnoses. Vasa 2015;44:166-77.

4. Garner R, Kumari R, Lanyon P, Doherty M, Zhang W. Prevalence, risk factors and associations of primary Raynaud's phenomenon: systematic review and meta-analysis of observational studies. BMJ Open 2015;5: e006389.

5. Manoria P, Joshi P, Sharma P, Jha RK. Systemic Sclerosis Sine Scleroderma. J Assoc Physicians India 2014;62:54-6. 